in einer durch Alkalien oder deren Carbonaten, so wie durch alkalische Erden basischen Flüssigkeit das Chlor zu bestimmen, so genügt Neutralisation mit Salpetersäure oder irgend einer andern unschädlichen Säure und falls diese im Ueberschuss zugegeben worden ist, Zusatz von Magnesiahydrat bis zur Alkalität.

\title{
Zur Anwendung des Phenolphthaleïns.
}

\section{Von Demselben.}

Das vor nicht langer Zeit von Luck zur Titrirung von Alkalien und Säuren als Indicator empfohlene Phenolphthaleïn, welches auch von anderer Seite zur Benutzung bei Sättigung kohlensaurer Alkalien mit Säure gerühmt worden ist, kann hierzu nur unter gewissen Umständen gebraucht werden, Alkalibicarbonate sind nämlich ohne Einwirkung auf dasselbe. Unbekannt hiermit wollte ich es bei der Bestimmung eines Essigs auf seinen Gehalt an Essigsäure anwenden und gab, nachdem ich die Lösung einer gewogenen Menge getrockneter reiner Soda in destillirtem Wasser einige Tropfen der Lösung des Phenolphthaleïns zugesetzt hatte, von dem zu untersuchenden Essig zu, schon nachdem ich etwa die Hälfte der Menge desselben zugesetzt hatte, die, wenn die Angabe des Fabrikanten über die Stärke des Essigs richtig war, nöthig gewesen wäre, verschwand die rothe Farbe, während auf weitern Zusatz von Essig lebhaftes Brausen von entweichender Kohlensäure erfolgte. Hierauf angestellte directe Versuche mit Kalibicarbonat bestätigten es, dass das Phenolphthaleïn ohne Einfluss auf Bicarbonate ist. Es ist desshalb erforderlich, dass bei Benutzung desselben als Indicator bei Sättigung von Alkalicarbonaten mit Säuren die Bildung von Bicarbonaten uabedingt vermieden werden muss. 